\title{
INFORMAÇÃO E INTERESSE PÚBLICO: QUANDO O JORNALISMO TORNA-SE UM MEIO PARA A CIDADANIA
}

\author{
Caio Barbosa Nascimento ${ }^{1}$
}

\begin{abstract}
RESUMO
Neste trabalho analisaremos a importância da informação jornalística para que as pessoas exerçam a sua cidadania na sociedade onde vivem e buscaremos compreender como o direito à informação no atual contexto midiático consiste num ponto fundamental para que se alcancem os demais direitos presentes numa democracia. Para tanto, fizemos um estudo sobre quais características da informação de interesse público fazem parte de sua identidade. Em nossa visão, essas informações seriam aquelas que são fruto da liberdade de expressão, que garantem ao receptor o direito à informação, sem se esquecer do direito à privacidade. Para ampliar essa compreensão, analisamos um produto do telejornalismo que seria a antítese de tudo isso e, desse modo, não teria condições de contribuir para a vivência cidadã dos indivíduos e para o bem comum de todos que vivem em sociedade. Com base nessa abordagem queremos apontar estratégias por meio das quais será possível atenuar as barreiras, para que o jornalismo, tal como apresentaremos, torne-se viável na mídia atual.
\end{abstract}

Palavras-chave: Cidadania. Interesse Público. Jornalismo.

${ }^{1}$ Graduando do Curso de Comunicação Social com habilitação em Jornalismo, VI Semestre, pela Universidade Estadual do Sudoeste da Bahia (UESB). E-mail: caiobn.j@gmail.com

\begin{tabular}{l|l|l|l|l}
\hline Revista Extensão \& Cidadania & Vitória da Conquista & v. 1, n. 1 & p. 143-158 & jan./jun. 2013 \\
\hline
\end{tabular}




\begin{abstract}
In this paper we analyze the importance of journalistic information for people to exercise their citizenship in society where they live. We seek to understand how the right to information in today's media, is a key point for achieving the other rights contained in a democracy. Pair this, we did a study on the characteristics of information of public interest that are part of their identity. In our view, this information would be those that are the fruit of freedom of expression, to ensure the receiver the right to information, without forgetting the right to privacy. Aiming to increase this understanding, we analyze a product of television journalism that would be the antithesis of all that and thus would not be able to contribute to the experiences of individuals and citizens for the common good of all who live in society.
\end{abstract}

Keywords: Citizenship. Public Interest. Journalism.

\title{
Um meio para a sociedade
}

Os meios de comunicação, sobretudo a internet, há algum tempo deixaram de ser parte de outro mundo que só entrava em contato com o nosso quando sentávamos diante do computador ou da televisão. A expressão "sociedade midiatizada" expressa corretamente como todas as nossas relações estão inseridas na dinâmica dos meios e como a nossa própria vida está estreitamente ligada aos dispositivos midiáticos.

Explica Lyon (2002, p. 10) que "faz pouco sentido hoje pensar em computadores e sistemas de comunicação como ferramentas. Eles fazem parte do contexto onde a vida é vivida". A importância do universo midiático cresce na medida em que a sociedade se torna mais complexa e as relações interpessoais ou no espaço público exigem o acesso aos meios de comunicação que, nesse sentido, potencializa a presença em sociedade.

Nesse contexto, o jornalismo ocupa um espaço de relevância ao tornar possível o contato das pessoas com informações atuais, sobre acontecimentos locais e mundiais em grande velocidade e por diferentes meios, alcançando, desse modo, grande parte da população do planeta. Segundo Gentilli (2002, p. 41), "contrariamente ao que ocorria no passado, é absolutamente inconcebível, nos dias que 
ocorrem, imaginar a possibilidade de vida nas modernas sociedades de massa sem a mediação informativa do jornalismo".

No Brasil, o telejornal tem uma ampla audiência e exerce um grande impacto na sociedade. Essa influência torna-se ainda mais clara se levarmos em conta o reduzido número de canais disponibilizados e o fato de as emissoras de TV, que utilizam concessões públicas por prazos determinados que podem ou não ser renovados, estarem nas mãos de poucos.

Sendo a informação e o jornalismo, de modo particular, indispensáveis no mundo atual, propomo-nos a analisar se o noticiário televisivo possui um jornalismo de interesse público, ancorado no tripé: liberdade de expressão, direito à informação e direito à privacidade e que, portanto, seja muito mais do que uma antítese ao "jornalismo privado", que atua com o interesse econômico, político, ideológico acima da informação, da verdade e da objetividade dos fatos.

Desse modo, é possível perceber que os responsáveis pela comunicação - seja o governo, a empresa, o jornalista ou o espectador - possuem um compromisso e um dever para com a sociedade, pois o direito à informação - e informação de interesse público - não possui um fim em si próprio: ele dá acesso a outros direitos que fazem parte da sociabilidade humana. Nesse sentido, compreendendo o jornalismo como ponto fundamental para a vida cidadã, será possível, por meio da análise de um programa da televisão brasileira, julgar em nosso contexto se o telejornalismo tem contribuído ou não para fomentar a cidadania em nossa sociedade.

Além disso, propomos em cada uma dessas grandes áreas um caminho que seja possível trilhar para que a ética seja preservada o mínimo possível nos noticiários. É evidente que não possuímos respostas definitivas para nenhum problema e, portanto, não buscaremos acabar com eles de uma vez por todas. Vamos apenas indicar por quais meios práticos esse tripé pode ser sustentado dentro da rotina das redações. 


\section{Direito à informação, direito à cidadania}

O conceito de democracia tem se transformado no decorrer da história. Ele faz parte de um processo de desenvolvimento da sociedade que se torna mais ou menos democrática na medida em que há maior ou menor participação popular no espaço público. Não podemos simplesmente afirmar que existe a sociedade democrática e a não democrática, como se seu sentido estivesse determinado em alguma norma de aceitação geral. Para que se compreenda essa ideia, Bobbio cita como exemplo o direito ao voto:

Uma sociedade na qual os que têm direito ao voto são os cidadãos masculinos maiores de idade é mais democrática do que aquela na qual votam apenas os proprietários e é menos democrática do que aquela em que têm direito ao voto também as mulheres. Quando se diz que no século passado ocorreu em alguns países um contínuo processo de democratização quer-se dizer que o número dos indivíduos com direito ao voto sofreu um progressivo alargamento (BOBBIO 1986 apud GENTILLI, 2002, p. 36).

O direito ao voto, nesse sentido, mostra-se como protótipo do amplo número de "direitos" que o cidadão ocidental, não sem muitos conflitos e disputas de poder, foi angariando no decorrer do tempo.

Atualmente, é o direito à informação que sustenta a democracia nas sociedades e garante ao indivíduo o acesso à cidadania. Esse acesso que antes tinha por base a natureza do indivíduo (homem, maior de idade) ou a quantidade de riquezas que possuía, em nossos dias está sustentado no conhecimento que a pessoa tem dos seus próprios direitos. Desse modo, percebemos que “o alargamento da participação na cidadania pressupõe um alargamento do direito à informação como uma premissa indispensável, um pressuposto" (GENTILLI, 2002, p. 43).

Essa constatação leva-nos a perguntar: atualmente, as pessoas têm acesso à informação? A que tipo de informação? Essa informação favorece o acesso à cidadania, de fato? 
Os meios de comunicação estão difundidos no mundo inteiro. Na maioria dos lares é possível encontrar rádio e TV, a internet já é uma realidade para grande parcela da população e se expande cada vez mais. Temos nesses diversos meios de comunicação muitas horas dedicadas ao jornalismo, atividade que busca, sobretudo, informar à população sobre aquilo que está acontecendo de mais importante, segundo os critérios de noticiabilidade já estabelecidos. Sendo assim, somos levados a responder positivamente à primeira pergunta, pois, como já dissemos antes, a característica marcante de nosso tempo é a midiatização da sociedade e das pessoas. Entretanto, quanto às outras perguntas, a resposta não é fácil, porque é necessário que a informação e jornalismo tenham certa característica e estejam condicionados, em nossa concepção, a algo fundamental: o interesse público.

Quando dizemos jornalismo de interesse público, não nos referimos àquele tipo de jornalismo feito por meios estatais, sejam impressos, radiofônicos, televisivos ou on-line noticiabilidade, tendo em vista oferecer aos membros da sociedade notícias acerca das últimas ações do governo em prol de todos. Todavia falamos de interesse público como algo que deva ser indispensável à atividade jornalística nos diversos meios disponibilizados e tornar o acesso à informação possível a todos que a buscam. O interesse público, desse modo, é inerente ao jornalismo, parte de sua identidade, sem a qual está necessariamente descaracterizado e incapaz de cumprir a sua finalidade, pois, "os meios de comunicação [...] devem ser regidos por uma ética que preserve, acima de tudo, os direitos dos cidadãos" (BUCCI, 2000, p. 11).

Dessa forma, é preciso que o interesse do cidadão seja levado em conta acima de outros interesses, sejam eles econômicos, políticos, ideológicos, governamentais, entre outros. Isso porque ter acesso à informação que lhe diga respeito e que promova o bem pessoal e social do homem é fundamental para que se consolide "o conjunto dos demais direitos posto que sua difusão, ao se tornar mais ampla, torna-se por conseqüência mais acessível” (GENTILLI, 2002, p. 43) 
Nesse sentido, o direito à informação não tem fim em si própria, mas é, segundo a expressão de Gentilli (2002, p. 43), um "direito-meio", que dá ao cidadão acesso aos seus demais direitos: sociais, políticos e civis.

\section{Jornalismo de Interesse Público}

Um jornalismo que busca em seu noticiário prestar um serviço para a comunidade responde desse modo, a uma exigência ética e assume novas responsabilidades perante o público que necessita, cada vez mais, dessa atividade profissional e dos meios de comunicação para existir como cidadão.

Cornu (1998) explica a afirmativa acima dizendo que o atual espaço público está submetido à atuação dos meios que exerce, com seu grande aparato de dispositivos, uma influência significativa nos diversos campos da cultura e da sociedade. Além disso, o autor afirma que muitas vezes os meios de comunicação agem em nome do público sem, na verdade, lhe dar vOz ou atuar em prol da sociedade e sem representar seus interesses. Ligado a isso, está o fato de que o indivíduo sozinho não tem condição de exercer sua liberdade de expressão política ou de outra natureza no espaço público, sendo em certa medida, dependente dos meios de comunicação.

Nesse sentido, os meios de comunicação dão ao cidadão acesso ao espaço público, "lugar simbólico onde se elaboram as normas coletivas e se fundamenta sua legitimidade" (CORNU, 1998, p. 155). Eles se tornam representantes do cidadão na luta pelos seus diretos diante de todo abuso de poder e também eles (os meios de comunicação) devem estar abertos à atuação e presença das pessoas. Contudo, é necessário que essa visão seja ponderada e equilibrada para que não se perca num "comunitarismo", no qual o indivíduo fique perdido ou outros assuntos sejam marginalizados.

Primeiro, é preciso compreender que a sociedade não é tão homogênea, mas se constitui de diversos grupos com pensamentos e ideias muitas vezes dissociadas. A pluralidade e a diversidade de 
pensamento é uma marca característica de nosso tempo e expressá-la nos meios de comunicação é muitas vezes sinônimo de credibilidade. Não é possível, entretanto, que haja contradição entre aquilo que é da pessoa, dos grupos e aquilo que é de todos. Martins Filho (2000, p. 3), explicando Santo Tomás de Aquino, diz que "o bem da comunidade é o bem do próprio individuo que a compõe". Desse modo, é possível também pensar a sociedade como humana para além das classes que a compõe, pois, segundo o autor "há uma certa unidade entre os participantes (da sociedade), como integrantes de um todo". Portanto, apesar do apelo a uma abordagem dos meios de comunicação que leve em conta a diversidade de perspectivas presentes na sociedade, é possível que haja um interesse público, algo sobre o qual a sociedade, como um todo, por estar constituída por homens, seja capaz de se interessar.

\section{Liberdade de Expressão}

Para que o jornalismo exista, a liberdade de expressão é um requisito básico e essencial. Para Cornu (1998), esse direito está ligado às condições de acesso aos meios de comunicação em seus diferentes dispositivos. Ele sinaliza na história da comunicação o direito de imprimir as concessões de TV e rádio a setores privados e sociais como partes de um processo que tornou a informação mais difundida em nossa sociedade e a consequente participação dos cidadãos no espaço público por meio desses canais.

A existência de meios (na sua dimensão material e tecnológica) assegurada em uma sociedade livre é fundamental para que a liberdade de expressão se exerça e seja cada vez mais ampla. Além disso, a possibilidade de utilizar esses meios para criticar "colocando em discussão pública questões de interesse da sociedade" (CORNU, 1998, p. 47) é o que dá sentido e conteúdo à liberdade de expressão. Não pode haver, portanto, uma limitação sobre a abordagem de acontecimentos relevantes que são essenciais e que dizem respeito à sociedade como um todo. Além da informação, propriamente dita, a liberdade de expressar opiniões, ideias e pensamentos é um direito fundamental, mas que, como todo direito não 
pode ser absoluto, antes regrado pela lei, pela verdade e, em certa medida, pelo direito também do outro.

Nesse sentido, somente um jornalismo resistente às pressões, em que interesses privativos de uns não prejudiquem o todo, um jornalismo que não seja submetido às fontes em troca de benefícios morais ou materiais, que lhes façam ocultar ou mentir quando comprados para calar ou falar, como também os meios que não confundam em seus noticiários a informação e a publicidade, no qual, portanto, cada um "esteja claramente identificado, com apresentação e tipografia que permitam ao leitor identificá-lo e distingui-lo" (CORNU, 1998, p. 58) e tenha, como diz o autor, "a verdade como fator fundamental da informação".

\section{Direito à Informação}

O direito à informação constitui o cerne de nossa discussão, na medida em que se apresenta na visão de alguns autores como o pressuposto básico da cidadania, sem o qual esta não se realiza. Esse direito se refere ao dever dos jornalistas em buscar a verdade dos fatos e de serem responsáveis por aquilo que é noticiado em seus veículos. $\mathrm{O}$ público tem o direito de receber informações que possam ser devidamente utilizadas para a vida em sociedade, e do mesmo modo o jornalismo tem uma função importante no aprendizado das pessoas. Aquilo que é noticiado, com o intuito apenas de informar, é também conhecimento com os quais crianças, jovens e adultos construirão o seu arcabouço intelectual e a sua identidade cultural. A informação é vista aqui como "matéria-prima [...] que interessa à cidadania". Se uma informação abarcar um amplo número de assuntos, que os analisa sob diversas perspectivas e que ao mesmo tempo está comprometida com o interesse da maioria das pessoas, a cidadania é então de fato promovida. Isso porque o acesso à vida pública tem como principal filtro, não necessariamente o único, o jornalismo.

É preciso que os meios de comunicação, sobretudo os jornalistas, estejam conscientes disso e se sintam responsáveis no cumprimento desse dever, que lhes foi confiado pela própria sociedade à qual eles se 
dirigem, pois, segundo Bucci (2000, p. 153) “[...] estes (os cidadãos) é que delegam a ele o direito de ser jornalista".

Queremos acrescentar aqui, a parcela de responsabilidade do próprio receptor na construção e na luta pelo seu direito à informação.

Se falarmos de cidadãos, não podemos pensar num indivíduo atomizado, um mero consumidor passivo diante não apenas do noticiário, mas da vida social como um todo. Ele é fator indispensável na execução de seu direito à informação. Isso pode acontecer, e acontece efetivamente, de vários modos. Cornu (1998) aponta dois pontos, um direto e outro indireto: primeiro, por meio da participação nas decisões públicas de cada país, seja aceitando as leis ou elegendo os seus representantes que são os responsáveis pela regulamentação da mídia; segundo, como consumidor, o público pode dar uma resposta direta aos agentes da comunicação da vendagem ou da audiência. Outra possibilidade, apontada pelo autor, é que as pessoas se reúnam em associações, criem instituições e se organizem de forma a exercerem juntos a pressão que sozinhos não lhes seria possível. Nessa perspectiva, podemos pensar também as redes sociais que ligam milhões de pessoas em todo o mundo e que já mostrou ter um grande potencial mobilizador, capaz de derrubar governos e, portanto, muito mais de fiscalizar e exigir uma atuação responsável da grande mídia. De qualquer forma:

[...] o público não pode ser eximido da responsabilidade de manter sobre estes (os meios de comunicação) um olhar crítico, que nunca deveria contentar-se, em termos de regulação, com a ação do Estado ou uma conformidade às leis do mercado, e muito menos com a simples fiscalização das instâncias reguladoras da profissão (CORNU, 1998, p. 180).

\section{Direito à privacidade}

Este é um tema controverso e recorrente na história do jornalismo. O fato é que a esfera pública está cada vez mais sendo invadida pela vida privada de várias pessoas. Boa parte do tempo e do 
espaço de que dispõe os meios é utilizada para narrar acontecimentos que nada contribuem para o bem comum ou estejam relacionados ao interesse público. É claro que, famosos, políticos e figuras públicas, muitas vezes, vivem fatos ou se envolvem em situações que dizem respeito à sociedade. Identificamos assim em cada pessoa um aspecto público e outro privado.

Se um político promove uma festa em sua casa, mas com os recursos dos cofres do Estado, este é um fato que interessa a todos e é relevante, sobretudo na hora de exercer o direito ao voto. Contudo, hoje em dia é montado um verdadeiro circo, em que casos minúsculos, ou sem relevância jornalística, da vida de pessoas são noticiados. O objetivo, muitas vezes comercial, é simplesmente explorar o "particular", um dos lados da pirâmide para atrair a atenção do público.

Isso causa um desequilíbrio na informação e não traz contribuição de nenhuma ordem para a sociedade. Pelo contrário, consiste num desrespeito à vida humana, não só para com quem se fala, mas, sobretudo, para com pessoas que são alvo desse tipo de atuação, que têm situações de sua vida invadidas e dramatizadas em jornais e revistas dos diversos meios.

Além do mais, é preciso notar que muitas vezes somos levados a imaginar a "invasão de privacidade" como algo apenas dos famosos e políticos. Entretanto, muitos programas sensacionalistas tiram sua "matéria-prima do drama de cidadãos humildes que aparecem nas delegacias como suspeitos de pequenos crimes" (BUCCI, 2000, p. 156). Essas pessoas muitas vezes não têm noção do que está acontecendo e parece que não possuem direito à privacidade, como diz Bucci: "sua intimidade não existe - ou não vale nada" (p. 156).

A superação das dificuldades encontradas na execução de tais propostas passa por várias vias, seja a acadêmica, ou mesmo a educação em geral para as pessoas. Contudo, um dos pontos mais importantes e que deve ser destacado é o setor financeiro. Os três pontos - liberdade de expressão, direito à informação e direito à privacidade - são intimamente ligados e é necessária uma ação que atinja os três para que seja possível promovê-los. 
O jornalismo em nosso tempo nunca foi tão dependente de anúncios publicitários. Não que eles sejam ruins em si, pois também são formas de comunicação e tem certa utilidade para as pessoas. No entanto, a forma como tem sido realizado e a influência sobre os meios são cada vez mais perniciosas. Quantas vezes a liberdade de expressão e o direito à informação têm sido cerceados, tendo em vista os interesses comerciais? E será que os jornais se importariam tanto com a vida de famosos e acontecimentos relacionados a sexo, morte e violência se não tivessem que vender tanto para publicizar os anunciantes? É preciso pensar seriamente na independência dos meios de comunicação em relação aos anúncios comerciais. Aumentar o valor dos periódicos ou cobrar alguma taxa para assistir aos canais de TV ou ouvir canais de rádio é um caminho viável, na medida em que os valores seriam divididos em uma população de quase 200 milhões de pessoas.

Além do mais, a informação se tornaria um bem de consumo em si próprio, ao invés de apenas apontar outros produtos em suas páginas. Desse modo, meio caminho estaria andado na construção de um jornalismo, quando aquilo que realmente importa para o cidadão a quem se dirigem os noticiários é exibido e publicado.

\section{Sensacionalismo X Interesse Público}

Um dos maiores empecilhos para que o interesse público seja levado em conta no jornalismo é a adoção de um "estilo" sensacionalista por vários veículos audiovisuais. Esse tipo de jornalismo seria, em nossa concepção, a antítese do jornalismo de interesse público na medida em que os diversos temas abordados (fait divers), bem como a linguagem utilizada e os possíveis efeitos que buscam causar no receptor não contribuem para o exercício da cidadania, nem para auxiliar na manutenção ou na construção de verdadeiros valores na sociedade.

Vamos analisar uma reportagem do programa Se liga Bocão, apresentado por José Eduardo (Bocão) às 12h, na TV Itapuan, afiliada da Rede Record na Bahia. No site oficial, o programa diz que se dedica 
a fazer reportagens caracterizadas por "depoimentos fortes, que muitas vezes chocam e emocionam o telespectador" e que "o programa mostra a realidade dos fatos sem maquiagem". ${ }^{2}$

Essa autodefinição está inserida no conceito de sensacionalismo que, ao contrário do que muitas pessoas pensam, não é simplesmente um jornalismo que em seu noticiário contém "audácia, irreverência, questionamentos, erro na apuração, distorção, deturpação, editorial agressivo" (ANGRIMANI SOBRINHO, 1995, p. 8). As características estão muitas vezes presentes em vários veículos de todos os tipos espalhados pela mídia e consistem, segundo o autor, em erros ou um exagero ocasional que não permanecem como padrão daquele meio.

Segundo Marcondes Filho (apud ANGRIMANI SOBRINHO, 1995, p. 9)

(A imprensa sensacionalista) "não se presta a informar, muito menos a formar. Presta-se básica e fundamentalmente a satisfazer as necessidades instintivas do público, por meio de formas sádicas, caluniadora e ridicularizadora das pessoas [...] servem mais para desviar o público de sua realidade imediata do que para voltar-se a ela.

Os elementos de estilo sensacionalista estão sempre presentes nesse tipo de noticiário. Apesar de terem um público fiel garantido e de, por vezes, abordarem assuntos de real importância, o modo pelo qual noticiam os fatos pretende apenas emocionar o público, chocar ou causar horror, sem proporcionar em momento algum a possibilidade de reflexão ou de questionamento: apenas de repulsa.

\section{Violência sexual: violência ao expectador}

Vamos analisar uma reportagem exibida pelo programa no dia 30 de Abril de 2009, quando a equipe do jornal foi até a cidade de Andaraí-Bahia para entrevistar um acusado que “[...] violentou uma jega (sic) e depois um garoto de 9 anos".

\footnotetext{
${ }^{2}$ Texto acessado no dia 13 de outubro de 2011. Disponível em: <http://www.itapoanonline. $\mathrm{com} / \mathrm{portal} / \mathrm{tv} / \mathrm{seligabocao} /$ programa.aspx $>$.
} 
O acontecimento em si é de grande importância, tanto social, jurídica, quanto jornalística. Entretanto, a abordagem é totalmente desequilibrada. Os fatos são apresentados para chocar o telespectador que desde o início já é provocado pelo âncora que diz: "Atenção! Essa é pesada". Antes de seguir para a matéria, o âncora utiliza uma estratégia para prender o público. Ele diz: “O que você vai ver agora está acontecendo aqui, pertinho de você... no seu lado". Esta é uma forma, segundo utiliza Agrimani Sobrinho (1995) baseado em Marcondes Filho, de extrair do fato, da notícia, toda a sua carga emotiva e apelativa para enaltecê-la e colocá-la em destaque diante dos olhos do espectador.

Durante a reportagem de quase 20 minutos, são entrevistados o acusado do abuso, o pai e a mãe da vítima, o próprio garoto e familiares ou pessoas ligadas a outras vítimas que não aparecem na reportagem.

O repórter não se limita a buscar as informações e noticiá-las. Depois de perguntar o que aconteceu e confirmar com o entrevistado que houve de fato um abuso sexual, ele pede: "relate pra mim, como foi que você fez isso? [...] relate mais ou menos como foi que você fez o ato lá com a criança, como foi? [...] conte, detalhadamente, o que foi que você fez, o que foi que você disse para ele tirar a roupa".

Como vimos anteriormente, a liberdade de expressão é fundamental para o jornalismo. Contudo, segundo Bucci (2000, p. 149) "onde não existe limite, não existe ética". Essa proposta do jornalista não compreende a liberdade de expressão, na verdade a tolhe na medida em que ela existe para fazer com que o cidadão participe do espaço público e tenha seus direitos representados nesse espaço. $\mathrm{O}$ interesse dessa matéria é "o lado aparente, externo, atraente do fato" (MARCONDES FILHO, 1986 apud ANGRIMANI SOBRINHO, 1995, p. 9) no qual a essência e o sentido verdadeiro da história e suas consequências ou implicações sociais se perdem e não recebem a devida atenção.

Em um segundo momento, o repórter decide saber sobre "a jega" que o homem também é acusado de violentar. As minúcias nas quais ele se detém são insignificantes para o jornalismo. Saber se "é a mesma 
jega?" que ele sempre tem relação ou se existe outras, além de péssimo gosto, é mais uma característica marcante do jornalismo sensacionalista que busca nos fait divers o insólito, o extravagante. Tal jornalismo exagera no destaque daquilo que é incomum na sociedade para, segundo a abordagem psicológica de Pedroso (1983 apud ANGRAMANI SOBRINHO, 1995, p. 20) "para ser consumido ou reconhecido como espetacular, perigoso, extravagante, insólito, por isso, atraente".

A justificativa para isso é muitas vezes o "direito à informação" que as pessoas possuem. Quando, na verdade, um espaço que poderia ser utilizado para informar e relatar acontecimentos sobre diversos outros temas de relevância muito menos duvidosa, é utilizado para suprir a carência por aquilo que Bucci (2000 p. 166) chama de "curiosidade perversa do público".

Durante a entrevista com os familiares do garoto e com o próprio garoto, o acontecimento deixa de ser simplesmente narrado e passa a ser dramatizado na televisão. Os elementos da matéria são elencados de tal forma, numa estratégia discursiva do grotesco, que faz desaparecer quase que completamente o direito à privacidade e à intimidade daquela família.

O foco nos detalhes, as perguntas embaraçosas e repetitivas que nada fazem a não ser constranger a família inteira (de classe baixa) levam a atenção do espectador para os detalhes mais sórdidos de uma violência sexual.

Se não há uma abordagem que seja capaz de passar do particular e alcançar também o todo, a informação torna-se desequilibrada, a dignidade e a vida das pessoas violentadas, o jornalismo enfraquecido e o cidadão incapaz de compreender a realidade dos fatos.

\section{Considerações Finais}

Por mais que possa haver controvérsias, no verdadeiro sentido de cidadania, compreendemos que em nosso atual contexto histórico e social ela está associada à comunicação e ao jornalismo, especificamente, 
por fazer comunicação em uma esfera maior em volume e amplitude do que todas as outras formas.

Todavia, para que haja verdadeira cidadania é preciso que haja verdadeiro jornalismo, que possibilite às pessoas acesso ao espaço público, dando-lhe voz, representando seus interesses na condição de indivíduos, membros de grupo e da sociedade e representando-os junto aos poderes públicos.

Desse modo, o jornalismo não pode ser considerado um simples adereço social, que traz informação e entretenimento para as pessoas, sem se preocupar com seus reais interesses. Não obstante, o acesso à informação de qualidade oferecida pelos seus dispositivos é o meio, segundo Gentilli (2002), para que se alcance o cidadão e os seus demais direitos.

Isso acontece porque o jornalismo é a história do presente. Os fatos e acontecimentos que têm maior importância, de um ponto de vista geral, são noticiados pelos seus veículos.

É possível, por exemplo, estudar nos livros de história que a Lei Áurea, assinada pela princesa Isabel em 1888, extinguiu a escravidão (oficialmente) no Brasil. Contudo, o conhecimento das novas leis, que são aprovadas e que dizem respeito ao indivíduo ou a seu grupo, só é possível ser obtido por um meio que veicule cotidianamente informações do atual.

É por esse motivo que o jornalismo é tão importante para a cidadania e para o cidadão em uma sociedade democrática. Os direitos conquistados pelos homens ou a luta por novos direitos é feita na arena pública, em que o acesso é possível apenas mediado por tais dispositivos de informação.

Na medida em que o interesse público é levado em conta, há uma verdadeira contribuição ou não para a vida em sociedade.

Não temos todas as respostas: quais direitos são mais privilegiados pela atuação da mídia? O que muda com o advento dos novos meios de comunicação, sobretudo com a internet? Será que as pessoas ainda necessitam dos meios tradicionais de comunicação para exercerem sua cidadania? $\mathrm{O}$ que compete, nesse processo, a cada um 
dos agentes da comunicação: governos, meios, empresas, jornalistas, população?

Essas são algumas das questões que ainda precisam ser analisadas e respondidas para que se compreenda com maior clareza esta intersecção entre meios de comunicação, informação de interesse público e cidadania.

\section{Referências}

ANGRIMANI SOBRINHO, Danilo. Espreme que sai sangue: um estudo do sensacionalismo na imprensa. São Paulo: Sumus, 1995.

BUCCI, Eugênio. Sobre ética e imprensa. São Paulo: Companhia das Letras, 2000.

CORNU, Daniel. Ética da informação. Tradução: Laureano Pelegrin. Bauru-SP: EDUSC, 1998.

GENTILLI, Victor. O conceito de cidadania, origens históricas e bases conceituais: os vínculos com a Comunicação. Revista FAMECOS, Porto Alegre, n. 19, dez. 2002. Quadrimestral. Disponível em: <http:// revistaseletronicas.pucrs.br/ojs/index.php/revistafamecos/article/ viewFile/3184/2451>. Acesso em: 10 out. 2011.

MARTINS FILHO, Ives Gandra da Silva. O princípio ético do bem comum e a concep̧cão jurídica do interesse público. Palestra proferida no Workshop Internacional sobre "Eficiência e Ética na Administração Pública". Brasilia, 2000. Disponível em: <http://www.dnit.gov.br/institucional/ comissao-de-etica/artigos-e-publicacoes/artigos-sobre-etica/O $\% 20$ Principio $\% 20$ Etico $\% 20$ do $\% 20$ Bem $\% 20$ Comum $\% 20 \mathrm{e} \% 20 \mathrm{a} \% 20$ Concepcao $\% 20 J$ uridica $\% 20 \mathrm{do} \% 20$ Interesse $\% 20$ Publico $\% 20$.pdf $>$. Acesso em: 3 out. 2011.

LYON, David. Cyberespace: Beyond the Information Society? In: ARMITAGE, John; ROBERTS, Joanne (Ed.). Livin With Cyberspace. Bodmin: Cornwall, 2002 . Tradução: Luiz Carlos Damasceno Junior. Disponível em: <http://members.fortunecity.com/cibercultura/ vol11/vol11_davidlyon.htm>. Acesso em: 2 out. 2011. 